\title{
Solutions of Nonlinear Integrodifferential \\ Equations of Mixed Type in Banach Spaces*
}

\author{
DAJUN GUO \\ Department of Mathematics \\ Shandong University \\ Jinan, People's Republic of China
}

\begin{abstract}
In this paper, the author combines the topological degree theory and the monotone iterative technique to investigate the existence of solutions and also minimal and maximal solutions of the initial value problem for nonlinear integrodifferential equations of mixed type in Banach space. Two main theorems are obtained and two examples are given.
\end{abstract}

Key words: Integrodifferential equations, topological degree theory, monotone iterative technique, measure of noncompactness

AMS subject classifications: $45 \mathrm{~J}, 47 \mathrm{G}$.

\section{INTRODUCTION}

Consider the IVP of the nonlinear integrodifferential equation of mixed type in the Banach space

$$
u^{\prime}=f(t, u, T u, S u), u(0)=u_{0},
$$

where $f \in \mathrm{C}[\mathrm{IxExExE}, \mathrm{E}], \mathrm{E}$ is a real Banach space, $\mathrm{I}=[0, a]$ with $a>0, u_{0} \in \mathrm{E}$ and

$$
T u(t)=\int_{0}^{t} k(t, s) u(s) d s, \quad S u(t)=\int_{0}^{a} h(t, s) u(s) d s .
$$

In (2), $k \in \mathrm{C}\left[\mathrm{D}, \mathrm{R}^{1}\right]$ and $h \in \mathrm{C}\left[\mathrm{D}_{0}, \mathrm{R}^{1}\right]$, where $\mathrm{D}=\left\{(t, s) \in \mathrm{R}^{2} \mid 0 \leq s \leq t \leq a\right\}$ and $\mathrm{D}_{0}=\left\{(t, s) \in \mathrm{R}^{2} \mid 0 \leq t, s \leq a\right\}$. In the special case where $f$ does not contain $T u$ and $S u$, the minimal and maximal solutions of (1) have been obtained by means of the monotone iterative technique in [1]. But, it is easy to see that the monotone iterative technique is not successful in the general case. Therefore, in this paper, we shall combine the topological

\footnotetext{
* Received: January 1989, Revised: March 1989
} 
degree theory and the monotone iterative technique to investigate the existence of solutions and also minimal and maximal solutions of the IVP (1). Two main theorems are obtained and two examples are given.

\section{A FUNDAMENTAL LEMMA}

Consider the nonlinear integral operator

$$
A u(t)=p(t) u_{0}+\int_{0}^{t} F(t, s, u(s), T u(s), S u(s)) d s
$$

where $p \in \mathrm{C}\left[\mathrm{I}, \mathrm{R}^{1}\right]$ and $F \in \mathrm{C}[\mathrm{DxExExE}, \mathrm{E}]$. Let $k_{0}=\max \{|k(t, s)| \mid(t, s) \in \mathrm{D}\}$ and $h_{0}=\max \left\{|h(t, s)| \mid(t, s) \in \mathrm{D}_{0}\right\}$.

LEMMA 1. Let $F$ be uniformly continuous on $\mathrm{DxB}_{\mathrm{R}} \times \mathrm{B}_{\mathrm{R}} \times \mathrm{B}_{\mathrm{R}}$ for any $\mathrm{R}>0$, where $B_{R}=\{x \in E \mid\|x\| \leq R\}$. Suppose that there exist $L_{i}>0(i=1,2,3)$ with

$$
a\left(L_{1}+a k_{0} L_{2}+a h_{0} L_{3}\right)<\frac{1}{2}
$$

such that

$$
\alpha(F(t, s, \mathrm{U}, \mathrm{V}, \mathrm{W})) \leq L_{1} \alpha(\mathrm{U})+L_{2} \alpha(\mathrm{V})+L_{3} \alpha(\mathrm{W})
$$

for any bounded $\mathrm{U}, \mathrm{V}, \mathrm{W} \subset \mathrm{E}$ and $(t, s) \in \mathrm{D}$, where $\alpha$ denotes the Kuratowski measure of noncompactness. Then, $A$ is a strict set contraction from $\mathrm{C}[\mathrm{I}, \mathrm{E}]$ into $\mathrm{C}[\mathrm{I}, \mathrm{E}]$, i.e. $A$ is bounded and continuous from $\mathrm{C}[\mathrm{I}, \mathrm{E}]$ into $\mathrm{C}[\mathrm{I}, \mathrm{E}]$ and there exists a real number $r$ strictly between 0 and 1 such that $\alpha(A(\mathrm{Q})) \leq r \alpha(\mathrm{Q})$ for any bounded $\mathrm{Q} \subset \mathrm{C}[\mathrm{I}, \mathrm{E}]$.

PROOF. It is easy to see that the uniform continuity of $F$ on $D \times B_{\mathrm{R}} \times B_{\mathrm{R}} \times B_{\mathrm{R}}$ implies the boundedness of $F$ on $\mathrm{DxB}_{\mathrm{R}} \times \mathrm{B}_{\mathrm{R}} \times \mathrm{B}_{\mathrm{R}}$, and so $A$ is a bounded and continuous operator from $C[I, E]$ into $C[I, E]$. The uniform continuity of $F$ and (5) imply (see [2] Lemma 1.4.1)

$$
\begin{aligned}
\alpha(F(t,[0, t], \mathrm{U}, \mathrm{V}, \mathrm{W})) & =\sup \{\alpha(F(t, s, \mathrm{U}, \mathrm{V}, \mathrm{W})) \mid 0 \leq s \leq t\} \\
& \leq L_{1} \alpha(\mathrm{U})+L_{2} \alpha(\mathrm{V})+L_{3} \alpha(\mathrm{W})
\end{aligned}
$$

for any bounded $U, V, W \subset E$. Let $Q \subset C[I, E]$ be bounded, i.e. there exists $R_{0}>0$ such that $\|u\|_{C}=\max \{\|u(t)\| \mid t \in I\} \leq \mathrm{R}_{0}$ for any $u \in \mathrm{Q}$. By the uniform continuity and boundedness of $F$ on $\mathrm{D} \times \mathrm{B}_{\mathrm{R}} \times \mathrm{B}_{\mathrm{R}} \times \mathrm{B}_{\mathrm{R}}$ with $\mathrm{R}=\max \left\{\mathrm{R}_{0}, a k_{0} \mathrm{R}_{0}, a h_{0} \mathrm{R}_{0}\right\}$, we can easily 
show that the functions $\{A u \mid u \in Q\}$ are uniformly bounded and equicontinuous; hence (see [2] Lemma 1.4.1)

$$
\alpha(A(\mathrm{Q}))=\sup \{\alpha(A(\mathrm{Q}(t))) \mid t \in \mathrm{I}\},
$$

where $A(\mathrm{Q}(t))=\{A u(t) \mid u \in \mathrm{Q}, t$ is fixed $\}$. Using formula

$$
\int_{I} x(t) d t \in|\mathrm{I}| \overline{\operatorname{co}}\{x(t) \mid t \in \mathrm{I}\} \quad \text { for } x \in \mathrm{C}[\mathrm{I}, \mathrm{E}]
$$

and observing (6), we get

$$
\begin{aligned}
\alpha(A(\mathrm{Q}(t))) & =\alpha\left\{\left\{\int_{0}^{t} F(t, s, u(s), T u(s), S u(s)) d s \mid u \in \mathrm{Q}\right\}\right) \\
& \leq t \alpha(\overline{\mathrm{co}}\{F(t, s, u(s), T u(s), S u(s)) \mid s \in[0, t], u \in \mathrm{Q}\}) \\
& =t \alpha\{f(t, s, u(s), T u(s), S u(s)) \mid s \in[0, t], u \in \mathrm{Q}\}) \\
& \leq t \alpha(F(t,[\mathrm{o}, t], \mathrm{U}, \mathrm{V}, \mathrm{W})) \\
& \leq t\left(L_{1} \alpha(\mathrm{U})+L_{2} \alpha(\mathrm{V})+L_{3} \alpha(\mathrm{W})\right),
\end{aligned}
$$

where $\mathrm{U}=\{u(s) \mid s \in \mathrm{I}, u \in \mathrm{Q}\}, \mathrm{V}=\{T u(s) \mid s \in \mathrm{I}, u \in \mathrm{Q}\}$ and $\mathrm{W}=\{S u(s) \mid s \in \mathrm{I}$, $u \in \mathrm{Q}\}$. Since $T u(s) \in s \overline{c o}\{k(s, y) \mathrm{u}(y) \mid y \in[0, s]\}$, we have

$$
\begin{aligned}
\mathrm{V} \subset \overline{\operatorname{co}}\{s k(s, y) u(y) \mid y \in[0, s], s \in \mathrm{I}, u \in \mathrm{Q}\} \\
\subset \overline{\operatorname{co}}\left\{a k_{0} u(y), \theta,-a k_{0} u(y) \mid y \in \mathrm{I}, u \in \mathrm{Q}\right\},
\end{aligned}
$$

where $\theta$ denotes the zero element of $\mathrm{E}$, and consequently

$$
\begin{aligned}
\alpha(\mathrm{V}) & \left.\leq \alpha\left\{a k_{0} u(y), \theta,-a k_{0} u(y) \mid y \in \mathrm{I}, u \in \mathrm{Q}\right\}\right) \\
& =a k_{0} \alpha\{\{u(y) \mid y \in \mathrm{I}, u \in \mathrm{Q}\}) \\
& =a k_{0} \alpha(\mathrm{U}) .
\end{aligned}
$$

Similarly, we find

$$
\alpha(\mathrm{W}) \leq a h_{0} \alpha(\mathrm{U})
$$

It follows from (7) - (10) that

$$
\alpha(A(\mathrm{Q})) \leq a\left(L_{1}+a k_{0} L_{2}+a h_{0} L_{3}\right) \alpha(\mathrm{U}) .
$$

On the other hand, for given $\varepsilon>0$, we can find a partition $\mathrm{Q}=\bigcup_{i=1}^{n} \mathrm{Q}_{i}$, satisfying 


$$
\operatorname{diam}\left(\mathrm{Q}_{i}\right)<\alpha(\mathrm{Q})+\varepsilon, i=1,2, \ldots, n .
$$

Choosing $u_{i} \in \mathrm{Q}_{i}(i=1,2, \ldots, n)$ and a partition $0=t_{0}<t_{1}<\ldots<t_{j-1}<t_{j}<\ldots<t_{m}$ such that

$$
\left\|u_{i}(t)-u_{i}(s)\right\|<\varepsilon \text { for } i=1,2, \ldots, n \text {, and } t, s \in \mathrm{I}_{j}=\left[t_{j-1}, t_{j}\right]
$$

$$
j=1,2, \ldots, m \text {. }
$$

Clearly, $\mathrm{U}=\bigcup_{j=1}^{m} \bigcup_{i=1}^{n} \mathrm{~B}_{i j}$, where $\mathrm{B}_{i j}=\left\{u(s) \mid u \in \mathrm{Q}_{i}, s \in \mathrm{I}_{j}\right\}$. For any two $x, y \in \mathrm{B}_{i j}$, we have $x=u(t)$ and $y=v(s)$ for some $u, v \in \mathrm{Q}_{i}$ and $t, s \in \mathrm{I}_{j}$. It follows from (12) and (13) that

$$
\begin{aligned}
\|x-y\| & \leq\left\|u(t)-u_{i}(t)\right\|+\left\|u_{i}(t)-u_{i}(s)\right\|+\left\|u_{i}(s)-v(s)\right\| \\
& \leq\left\|u-u_{i}\right\|_{\mathrm{C}}+\varepsilon+\left\|u_{i}-v\right\|_{\mathrm{C}} \\
& \leq 2 \operatorname{diam}\left(\mathrm{Q}_{i}\right)+\varepsilon<2 \alpha(\mathrm{Q})+3 \varepsilon .
\end{aligned}
$$

Consequently,

$$
\operatorname{diam}\left(\mathrm{B}_{i j}\right) \leq 2 \alpha(\mathrm{Q})+3 \varepsilon, i=1,2, \ldots, n \text { and } j=1,2, \ldots, m,
$$

and therefore

$$
\alpha(\mathrm{U}) \leq 2 \alpha(\mathrm{Q})+3 \varepsilon
$$

which implies

$$
\alpha(\mathrm{U}) \leq 2 \alpha(\mathrm{Q}),
$$

since $\varepsilon$ is arbitrary. Finally, it follows from (11), (14) and (4) that $\alpha(A(\mathrm{Q})) \leq r \alpha(\mathrm{Q})$ with $r=2 a\left(L_{1}+a k_{0} L_{2}+a h_{0} L_{3}\right)<1$. This shows that $A$ is a strict set contraction and the Lemma is proved.

\section{MAIN THEOREMS}

THEOREM 1. Let $f$ be uniformly continuous on $\mathrm{IxB}_{\mathrm{R}} \times \mathrm{B}_{\mathrm{R}} \times \mathrm{B}_{\mathrm{R}}$ for any $\mathrm{R}>0$. Assume that there exist $\mathrm{L}_{i}>0(i=1,2,3)$, which satisfy (4), such that

$$
\alpha(f(t, \mathrm{U}, \mathrm{V}, \mathrm{W})) \leq L_{1} \alpha(\mathrm{U})+L_{2} \alpha(\mathrm{V})+L_{3} \alpha(\mathrm{W})
$$

for any bounded $U, V, W \subset E$ and $t \in I$. Assume further

$$
\varlimsup_{\mathrm{R} \rightarrow+\infty} \frac{M(\mathrm{R})}{\mathrm{R}}<\left(a a_{0}\right)^{-1}
$$


where $M(\mathrm{R})=\sup \left\{\|f(t, u, v, w)\| \mid(t, u, v, w) \in \mathrm{IxB}_{\mathrm{R}} \times \mathrm{B}_{\mathrm{R}} \times \mathrm{B}_{\mathrm{R}}\right\}$ and $a_{0}=\max \left\{1, a k_{0}, a h_{0}\right\}$. Then IVP (1) has at least one solution in $\mathrm{C}^{1}[\mathrm{I}, \mathrm{E}]$.

PROOF. It is well known that $u$ is a solution of IVP (1) in $C^{1}[\mathrm{I}, \mathrm{E}]$ iff $u$ is a solution in $\mathrm{C}[\mathrm{I}, \mathrm{E}]$ of the following integral equation:

$$
u(t)=u_{0}+\int_{0}^{t} f(s, u(s), T u(s), S u(s)) d s .
$$

Let

$$
A u(t)=u_{0}+\int_{0}^{t} f(s, u(s), T u(s), S u(s)) d s .
$$

By virtue of Lemma 1, $A$ is a strict set contraction from $C[I, E]$ into $C[I, E]$. On the other hand, (16) implies the existence of a real $r$ strictly between 0 and $\left(a a_{0}\right)^{-1}$ and $\mathrm{R}_{0}>0$ such that

$$
\frac{M(\mathrm{R})}{\mathrm{R}}<r \quad \text { for } \mathrm{R} \geq a_{0} \mathrm{R}_{0} .
$$

Let $\mathrm{R}^{*}=\max \left\{\mathrm{R}_{0},\left\|u_{0}\right\|\left(1-a a_{0} r\right)^{-1}\right\}$. Then, for $\mathrm{u} \in \mathrm{C}[\mathrm{I}, \mathrm{E}]$ and $\|\mathrm{u}\|_{\mathrm{C}} \leq \mathrm{R}^{*}$, we have

$$
\|T u\|_{C} \leq a k_{0}\|u\|_{C} \leq a k_{0} R^{*}, \quad\|S u\|_{C} \leq a h_{0}\|u\|_{C} \leq a h_{0} R^{*},
$$

and therefore, by (18) and (19),

$$
\|A u\|_{\mathrm{C}} \leq\left\|u_{0}\right\|+a M\left(a_{0} \mathrm{R}^{*}\right)<\left\|u_{0}\right\|+a a_{0} \mathrm{R}^{*} r \leq \mathrm{R}^{*} .
$$

Hence, by the Darbo fixed point theorem (see [3]), $A$ has a fixed point in the ball $\left\{u \in \mathrm{C}[\mathrm{I}, \mathrm{E}] \mid\|u\|_{\mathrm{C}} \leq \mathrm{R}^{*}\right\}$.

EXAMPLE 1. Consider the IVP of the infinite system of sublinear integrodifferential equations

$$
\begin{aligned}
& u_{n}^{\prime}=\frac{3 t^{2}}{n}\left(u_{n+1}+2 u_{2 n} \int_{0}^{t} e^{t s} \sin (t-2 s) u_{n}(s) d s-1\right)^{\frac{1}{3}} \\
& \quad-\frac{2}{n+1}\left(u_{n}^{2} \int_{0}^{1} \cos \pi(t-s) u_{n+1}(s) d s\right)^{\frac{1}{5}}, 0 \leq t \leq 1 \\
& u_{n}(0)=\frac{1}{\sqrt{n}} \quad(n=1,2,3 \ldots) .
\end{aligned}
$$


Then IVP (20) has at least one continuously differentiable solution $\left\{u_{1}(t), u_{2}(t), \ldots, u_{n}(t), \ldots\right\}$ such that $u_{n}(t) \rightarrow 0$ as $n \rightarrow \infty$ for and $t \in[0,1]$. To show this, we let $a=1$ and $\mathrm{E}=c_{0}=\left\{u=\left(u_{1}, u_{2}, \ldots, u_{n}, \ldots\right) \mid u_{n} \rightarrow 0\right\}$ with norm $\|u\|=\sup _{n}\left|u_{n}\right|$. Then, system (20) can be regarded as an equation of the form (1), where $u_{0}=\left(1, \frac{1}{\sqrt{2}}, \ldots . \frac{1}{\sqrt{n}}\right.$ $, \ldots), k(t, s)=e^{t s} \sin (t-2 s), h(t, s)=\cos \pi(t-s), u=\left(u_{1}, u_{2}, \ldots, u_{n}, \ldots\right), v=$ $\left(v_{1}, v_{2}, \ldots, v_{n}, \ldots\right), w=\left(w_{1}, w_{2}, \ldots, w_{n}, \ldots\right)$ and $f=\left(f_{1} f_{2}, \ldots, f_{n}, \ldots\right)$, in which

$$
\begin{gathered}
f_{n}(t, u, v, w)=\frac{3 t^{2}}{n}\left(u_{n+1}+2 u_{2 u} v_{n}-1\right)^{\frac{1}{3}}-\frac{2}{n+1}\left(u_{n}^{2} w_{n+1}\right)^{\frac{1}{5}}, \\
(n=1,2,3, \ldots) .
\end{gathered}
$$

On account of (21), we have

$$
\begin{gathered}
\left|f_{n}(t, u, v, w)\right| \leq \frac{3}{n}(\|u\|+2\|u\| \cdot\|v\|+1)^{\frac{1}{3}}+\frac{2}{n+1}\|u\|^{\frac{2}{5}} \cdot\|w\|^{\frac{1}{5}}, \\
(t \in \mathrm{I}, n=1,2,3, \ldots),
\end{gathered}
$$

and so

$$
\|f(t, u, v, w)\| \leq 3(\|u\|+2\|u\| \cdot\|v\|+1)^{\frac{1}{3}}+\|u\|^{\frac{2}{5}} \cdot\|w\|^{\frac{1}{5}} .
$$

Hence

$$
M(\mathrm{R}) \leq 3\left(\mathrm{R}+2 \mathrm{R}^{2}+1\right)^{\frac{1}{3}}+\mathrm{R}^{\frac{3}{5}}
$$

and consequently,

$$
\lim _{\mathrm{R} \rightarrow+\infty} \frac{M(\mathrm{R})}{\mathrm{R}}=0 .
$$

This implies that (16) is satisfied since $1<k_{0}<e, h_{0}=1$ and $a_{0}=k_{0}$. Obviously, $f$ is uniformly continuous on $\mathrm{IxB}_{R} \times \mathrm{B}_{\mathrm{R}} \times \mathrm{B}_{R}$ for any $\mathrm{R}>0$ and, by virtue of (22), it is easy to show that the set $f(t, \mathrm{U}, \mathrm{V}, \mathrm{W})$ is relatively compact in $\mathrm{E}=c_{0}$ for any bounded $\mathrm{U}, \mathrm{V}, \mathrm{W} \subset \mathrm{E}$ and $t \in \mathrm{I}=[0,1]$; and therefore (15) and (4) are satisfied for $L_{1}=L_{2}=L_{3}=0$. Hence, our conclusion follows from Theorem 1 .

In the following, let $\mathrm{P}$ be a cone in $\mathrm{E}$, and then $\mathrm{P}$ define a partial order in $\mathrm{E}: x \leq y$ iff $y-x \in \mathrm{P}$ (see [4]). $u \in \mathrm{C}^{\mathrm{l}}[\mathrm{I}, \mathrm{E}]$ is called a lower (upper) solution of (1) if $u^{\prime} \leq f(t, u, T u, S u)$ for $t \in \mathrm{I}$ and $u(0) \leq u_{0}\left(u^{\prime} \geq f(t, u, T u, S u)\right.$ for $t \in \mathrm{I}$ and $\left.u(0) \geq u_{0}\right)$. 
THEOREM 2. Let $f$ be uniformly continuous on $\mathrm{IxB}_{\mathrm{R}} \times \mathrm{B}_{\mathrm{R}} \times \mathrm{B}_{\mathrm{R}}$ for any $\mathrm{R}>0, k(t, s)$ $\geq 0$ for $(t, s) \in \mathrm{D}$ and $h(t, s) \geq 0$ for $(t, s) \in \mathrm{D}_{0}$. Let cone $\mathrm{P}$ be normal and $y_{0}(t)$ and $z_{0}(t)$ be lower and upper solutions of (1) respectively with $y_{0}(t) \leq z_{0}(t)$ and $t \in \mathrm{I}$. Suppose that there exist $M>0$ and $L_{i}>0(i=1,2,3, \ldots)$ with

$$
a\left(M+L_{1}+a k_{0} L_{2}+a h_{0} L_{3}\right)<\frac{1}{2}
$$

such that

$$
f(t, u, v, w)-f(t, \bar{u}, \bar{v}, \bar{w}) \geq-M(u-\bar{u})
$$

$$
\begin{gathered}
\text { for } t \in \mathrm{I}, y_{0}(t) \leq \bar{u} \leq u \leq z_{0}(t), T y_{0}(t) \leq \bar{v} \leq v \leq T z_{0}(t), \\
\qquad \begin{array}{c}
S y_{0}(t) \leq \bar{w} \leq w \leq S z_{0}(t) \text {, and } \\
\alpha(f(t, \mathrm{U}, \mathrm{V}, \mathrm{W})) \leq L_{1} \alpha(\mathrm{U})+L_{2} \alpha(\mathrm{V})+L_{3} \alpha(\mathrm{W})
\end{array}
\end{gathered}
$$

for any bounded $\mathrm{U}, \mathrm{V}, \mathrm{W} \subset \mathrm{E}$ and $t \in \mathrm{I}$. Then IVP (1) has minimal solution $u_{*}(t)$ and maximal solution $u^{*}(t)$ in $\left[y_{0}, z_{0}\right]$; and $y_{n}(t) \rightarrow u_{*}(t)$ and $z_{n}(t) \rightarrow u^{*}(t)$ as $n \rightarrow \infty$ uniformly in $t \in \mathrm{I}$, where

$$
y_{n}(t)=u_{0} e^{-M t}+\int_{0}^{t} e^{-M(t-s)}\left[f\left(s, y_{n-1}(s), T y_{n-1}(s), S y_{n-1}(s)\right)+M y_{n-1}(s)\right] d s
$$

and

$$
\begin{gathered}
z_{n}(t)=u_{0} e^{-M t}+\int_{0}^{t} e^{-M(t-s)}\left[f\left(s, z_{n-1}(s), T z_{n-1}(s), S z_{n-1}(s)\right)+M z_{n-1}(s)\right] d s, \\
n=1,2,3, \ldots,
\end{gathered}
$$

which satisfy

$$
\begin{aligned}
y_{0}(t) & \leq y_{1}(t) \leq \ldots \leq y_{n}(t) \leq \ldots \leq u_{*}(t) \leq u^{*}(t) \leq \ldots \\
& \leq z_{n}(t) \leq \ldots \leq z_{1}(t) \leq z_{0}(t), t \in \mathrm{I} .
\end{aligned}
$$

PROOF. For any $x \in\left[y_{0}, z_{0}\right] \subset \mathrm{C}[\mathrm{I}, \mathrm{E}]$, it is easy to see that the linear IVP

$$
u^{\prime}=f(t, x, T x, S x)-M(u-x), u(0)=\mathrm{u}_{0}
$$

has an unique solution in $C^{1}[\mathrm{I}, \mathrm{E}]$ given by

$$
u(t)=u_{0} e^{-M t}+\int_{0}^{t} e^{-M(t-s)}(f(s, x(s), T x(s), S x(s))+M x(s)) d s .
$$


Define operator $A$ by

$$
A x(t)=u_{0} e^{-M t}+\int_{0}^{t} e^{-M(t-s)}(f(s, x(s), T x(s), S x(s))+M x(s)) d s .
$$

It is evident that $u$ is a solution of (1) (in $C^{1}[I, E]$ ) iff $u$ is a fixed point of $A$ in $C[I, E]$. By virtue of (26), we see that $y_{0} \leq x_{1} \leq x_{2} \leq z_{0}$ implies that

$$
f\left(t, x_{1}(t), T x_{1}(t), S x_{1}(t)\right)+M x_{1}(t) \leq f\left(t, x_{2}(t), T x_{2}(t), S x_{2}(t)\right)+M x_{2}(t), \quad t \in I ;
$$

and therefore, observing (33), we have that $A$ is a nondecreasing operator from $\left[y_{0}, z_{0}\right]$ into $\mathrm{C}[\mathrm{I}, \mathrm{E}]$.

$$
\begin{aligned}
& \text { Now, let } y_{1}=A y_{0} \text { and } \bar{y}=y_{1}-y_{0} \text {. Then } \\
& \bar{y}^{\prime}=y_{1}^{\prime}-y_{0}^{\prime}=f\left(t, y_{0}, T y_{0}, S y_{0}\right)-M\left(y_{1}-y_{0}\right)-y_{0}^{\prime} \\
& \geq f\left(t, y_{0}, T y_{0}, S y_{0}\right)-M \bar{y}-f\left(t, y_{0}, T y_{0}, S y_{0}\right) \\
& =-M y, t \in \mathrm{I} \text {; } \\
& \bar{y}(0)=y_{1}(0)-y_{0}(0) \geq u_{0}-u_{0}=\theta \text {, and } \\
& \left(\bar{y}(t) e^{M t}\right)^{\prime}=\left[\bar{y}^{\prime}(t)+M \bar{y}(t)\right] e^{M t} \geq \theta, t \in \mathrm{I} \text {. }
\end{aligned}
$$

And therefore

$$
\bar{y}(t) e^{M t}=\bar{y}(0)+\int_{0}^{t}\left(\bar{y}(s) e^{M s}\right)^{\prime} d s \geq \theta, \quad t \in \mathrm{I} .
$$

Hence, $\bar{y}(t) \geq \theta, t \in I$; i.e. $A y_{0} \geq y_{0}$. Similarly, we can show $A z_{0} \leq z_{0}$.

On the other hand, let

$$
p(t)=e^{-M t} \text { and } F(t, s, u, v, w)=e^{-M(t-s)} f_{1}(s, u, v, w),
$$

where $f_{1}(s, u, v, w)=f(s, u, v, w)+M u$. Then, $F$ is uniformly continuous on $\mathrm{D} \times \mathrm{B}_{\mathrm{R}} \times \mathrm{B}_{\mathrm{R}} \times \mathrm{B}_{\mathrm{R}}$ for any $\mathrm{R}>0$ and, observing (27) and the fact that $0<e^{-M(t-s)} \leq 1$ for $(t, s) \in \mathrm{D}$, we have

$$
\begin{aligned}
\alpha(F(t, s, \mathrm{U}, \mathrm{V}, \mathrm{W})) & \leq \alpha\left(\overline{\mathrm{co}}\left\{f_{1}(s, \mathrm{U}, \mathrm{V}, \mathrm{W}), \theta\right\}\right) \\
& =\alpha\left(f_{1}(s, \mathrm{U}, \mathrm{V}, \mathrm{W})\right) \\
& \leq\left(L_{1}+M\right) \alpha(\mathrm{U})+L_{2} \alpha(\mathrm{V})+L_{3} \alpha(\mathrm{W})
\end{aligned}
$$

for any bounded $\mathrm{U}, \mathrm{V}, \mathrm{W} \subset \mathrm{E}$ and $(t, s) \in \mathrm{D}$. This inequality together with (25) implies, by Lemma 1 , that $A$ is a strict set contraction from $C[I, E]$ into $C[I, E]$. Finally, our 
conclusions follow from a fixed point theorem due to Amann (see [5], Theorem 3).

EXAMPLE 2. Consider the IVP of the infinite system of superlinear integrodifferential equations

$$
\begin{aligned}
& u_{n}^{\prime}=\frac{1}{8 n}\left[\left(t-u_{n}\right)^{3}+u_{2 n+1}^{4}\right]+\frac{5}{\sqrt{n}}\left[\int_{0}^{t} \sin ^{2}(t-3 s) u_{2 n}(s) d s\right]^{2} \\
& \quad+\frac{1}{2 n}\left[\int_{0}^{1} e^{t s} u_{n+1}(s) d s\right]^{3}, 0 \leq t \leq 1 ; \\
& u_{n}(0)=0 \quad(n=1,2,3, \ldots) .
\end{aligned}
$$

Then IVP (34) has minimal and maximal continuously differentiable solutions satisfying $0 \leq u_{n}(t) \leq \frac{t}{n}(t \in[0,1], n=1,2,3, \ldots)$.

To show this let $a=1, \mathrm{E}=c_{0}=\left\{u=\left(u_{1}, u_{2}, u_{3}, \ldots, u_{n}, \ldots\right) \mid u_{n} \rightarrow 0\right\}$ with norm $\|u\|=\sup _{n}\left|u_{n}\right|$ and $\mathrm{P}=\left\{u=\left(u_{1}, u_{2}, \ldots, u_{n}, \ldots\right) \in c_{0} \mid u_{n} \geq 0, n=1,2,3, \ldots\right\}$. Then, $\mathrm{P}$ is a normal cone in $c_{0}$ and system (34) can be regarded as an equation of the form (1). In this situation $u_{0}=(0,0, \ldots, 0, \ldots), \quad k(t, s)=\sin ^{2}(t-3 s), \quad h(t, s)=e^{t s}$, $u=\left(u_{1}, u_{2}, \ldots, u_{n}, \ldots\right), v=\left(v_{1}, v_{2}, \ldots, v_{n}, \ldots\right), w=\left(w_{1}, w_{2}, \ldots, w_{n}, \ldots\right)$ and $f=\left(f_{1} f_{2}, \ldots f_{n}, \ldots\right)$, in which

$$
\begin{gathered}
f_{n}(t, u, v, w)=\frac{1}{8 n}\left[\left(t-u_{n}\right)^{3}+u_{2 n+1}^{4}\right]+\frac{5}{\sqrt{n}} v_{2 n}^{2}+\frac{1}{2 n} w_{n+1}^{3} \\
(n=1,2,3, \ldots) .
\end{gathered}
$$

Equalities in (35) imply

$$
\begin{gathered}
\left|f_{n}(t, u, v, w)\right| \leq \frac{1}{8 n}\left[(t+\|u\|)^{3}+\|u\|^{4}\right]+\frac{5}{\sqrt{n}}\|v\|^{2}+\frac{1}{2 n}\|w\|^{3} \\
(t \in \mathrm{I}, \mathrm{I}=[0,1], n=1,2,3, \ldots) .
\end{gathered}
$$

It is clear that $f$ is uniformly continuous on $\operatorname{IxB}_{R} \times B_{R} \times B_{R}$ for any $R>0$; and by virtue of (35) and (36), we can easily prove that $f(t, \mathrm{U}, \mathrm{V}, \mathrm{W})$ is relatively compact in $\mathrm{E}=c_{0}$ for any bounded U,V,W $\subset \mathrm{E}$ and $t \in \mathrm{I}$. Hence, (27) is satisfied for $L_{1}=L_{2}=L_{3}=0$. Let $y_{0}(t)=(0,0, \ldots, 0, \ldots)$ and $z_{0}(t)=\left(t, \frac{t}{2}, \ldots, \frac{t}{n}, \ldots\right)$ for $t \in \mathrm{I}$. Then $y_{0}(t) \leq z_{0}(t), t \in \mathrm{I}$. 


$$
\begin{aligned}
& y_{0}(0)=z_{0}(0)=(0,0, \ldots, 0, \ldots)=u_{0} \text { and } \\
& y_{0}^{\prime}(t)=(0,0, \ldots, 0, \ldots), t \in \mathrm{I} \text {. } \\
& z_{0}^{\prime}(t)=\left(1, \frac{1}{2}, \ldots, \frac{1}{n}, \ldots\right), t \in \mathrm{I} \text {. } \\
& f_{n}\left[t, y_{0}(t), T y_{0}(t), S y_{0}(t)\right]=\frac{t^{3}}{8 n} \geq 0 \quad(t \in \mathrm{I}, n=1,2,3, \ldots) \text {. } \\
& f_{n}\left[t, z_{0}(t), T z_{0}(t), S z_{0}(t)\right]=\frac{1}{8 n}\left(\left(t-\frac{t}{n}\right)^{3}+\left(\frac{t}{2 n+1}\right)^{4}\right) \\
& +\frac{5}{\sqrt{n}}\left(\int_{0}^{t} \frac{s}{2 n} \sin ^{2}(t-3 s) d s\right)^{2} \\
& +\frac{1}{2 n}\left(\int_{0}^{1} \frac{s e^{t s}}{n+1} d s\right)^{3} \\
& <\frac{1}{4 n}+\frac{5}{16 n^{2} \sqrt{n}}+\frac{e^{3}}{16 n(n+1)^{3}} \\
& <\frac{1}{n} \quad(t \in \mathrm{I}, n=1,2,3, \ldots) \text {. }
\end{aligned}
$$

Consequently, $\mathrm{y}_{0}$ and $\mathrm{z}_{0}$ are lower and upper solutions of (34) respectively.

When $t \in \mathrm{I}, y_{0}(t) \leq \bar{u} \leq u \leq z_{0}(t), T y_{0}(t) \leq \bar{v} \leq v \leq T z_{0}(t)$, and $S y_{0}(t) \leq \bar{w} \leq w \leq S z_{0}(t)$, i.e.

$$
\begin{aligned}
& 0 \leq \bar{u}_{n} \leq u_{n} \leq \frac{t}{n}, \\
& 0 \leq \bar{v}_{n} \leq v_{n} \leq \int_{0}^{t} \frac{s}{n} \sin ^{2}(t-3 s) d s \leq \frac{t^{2}}{2 n}, \text { and } \\
& 0 \leq \bar{w}_{n} \leq w_{n} \leq \int_{0}^{1} \frac{s}{n} e^{t s} d s \leq \frac{e}{2 n} \quad(t \in \mathrm{I}, n=1,2,3, \ldots),
\end{aligned}
$$

we have 


$$
\begin{aligned}
f_{n}(t, u, v, w)-f_{n}(t, \bar{u}, \bar{v}, \bar{w})= & \frac{1}{8 n}\left[\left(t-u_{n}\right)^{3}+u_{2 n+1}^{4}-\left(t-\bar{u}_{n}\right)^{3}-\bar{u}_{2 n+1}^{4}\right] \\
& +\frac{5}{\sqrt{n}}\left(v_{2 n}^{2}-\bar{v}_{2 n}^{2}\right)+\frac{1}{2 n}\left(w_{n+1}^{3}-\bar{w}_{n+1}^{3}\right) \\
\geq & \frac{1}{8 n}\left[\left(t-u_{n}\right)^{3}-\left(t-\bar{u}_{n}\right)^{3}\right] \\
\geq & -\frac{3}{8 n}\left(u_{n}-\bar{u}_{n}\right) \\
\geq & -\frac{3}{8}\left(u_{n}-\bar{u}_{n}\right) \\
(n & =1,2,3, \ldots) \\
\text { (since } \frac{\partial}{\partial s}(t-s)^{3}=-3(t-s)^{2} \geq & -3 \quad \text { for } 0 \leq s \leq t, 0 \leq t \leq 1) .
\end{aligned}
$$

Consequently, (26) is satisfied for $M=\frac{3}{8}$. Moreover

$$
a\left(M+L_{1}+a k_{0} L_{2}+a h_{0} L_{3}\right)=a M=\frac{3}{8}<\frac{1}{2} ;
$$

this shows that (25) is also satisfied. Hence, our conclusion follows from Theorem 2.

\section{REFERENCES}

[1] Du, S.W. and V. Lakshmikantham, Monotone Iterative Technique for Differential Equations in a Banach Space, J.Math.Anal.Appl., 87(1982) 454-459.

[2] Lakshmikantham, V., S. Leela, Nonlinear Differential Equations in Abstract Spaces, Pergamon Press, Oxford (1981).

[3] Guo, Dajun, Nonlinear Functional Analysis, Shandong Sci. and Tech. Press, Jinan, 1985 (Chinese).

[4] Guo, Dajun, V. Lakshmikantham, Nonlinear Problems in Abstract Cones, Academic Press Boston, New York (1988).

[5] Amann, H., On the Number of Solutions of Nonlinear Equations in Ordered Banach Spaces, J.Funct.Anal., 11(1972) 346-384. 


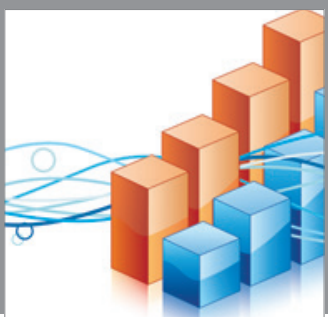

Advances in

Operations Research

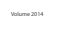

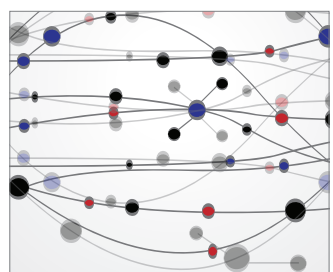

\section{The Scientific} World Journal
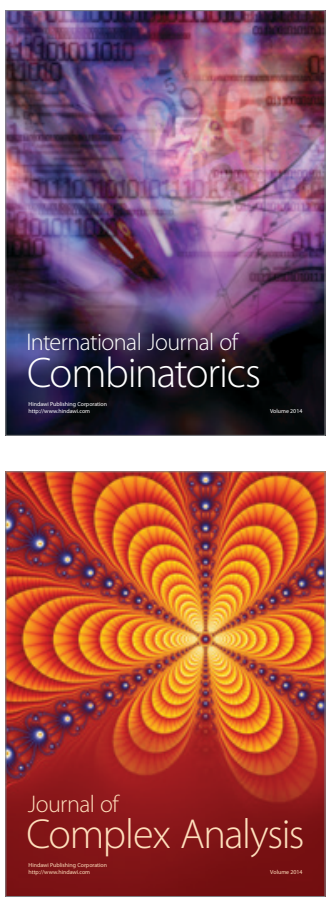

International Journal of

Mathematics and

Mathematical

Sciences
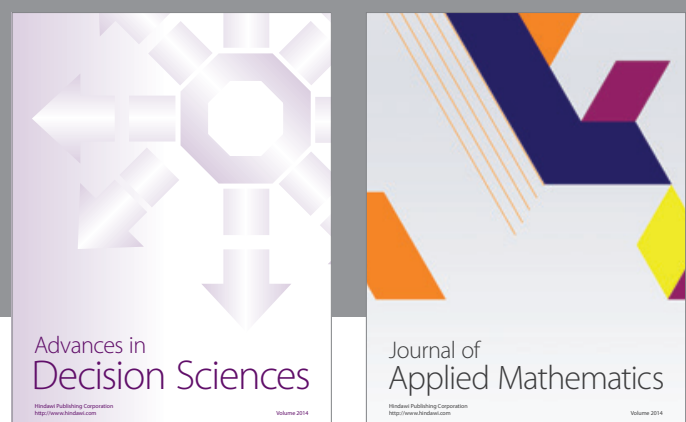

Journal of

Applied Mathematics
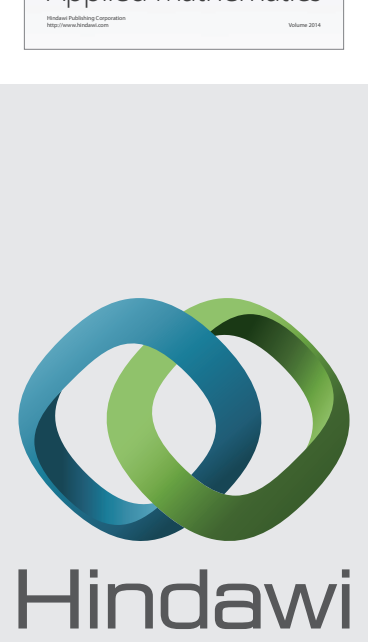

Submit your manuscripts at http://www.hindawi.com
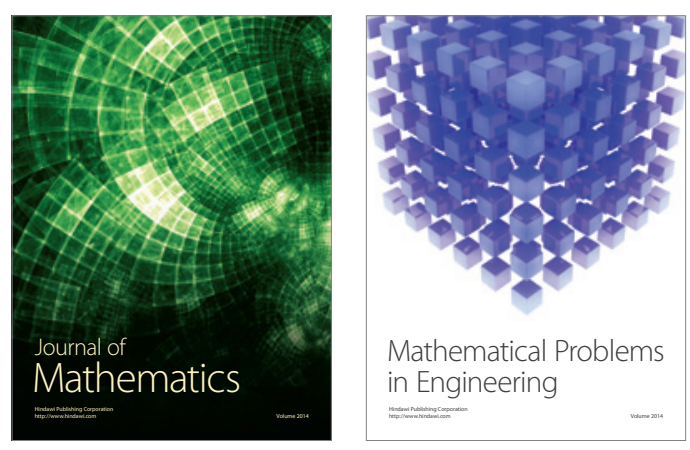

Mathematical Problems in Engineering
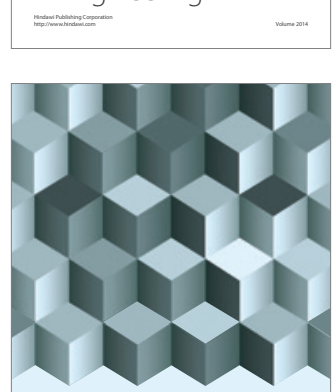

Journal of

Function Spaces
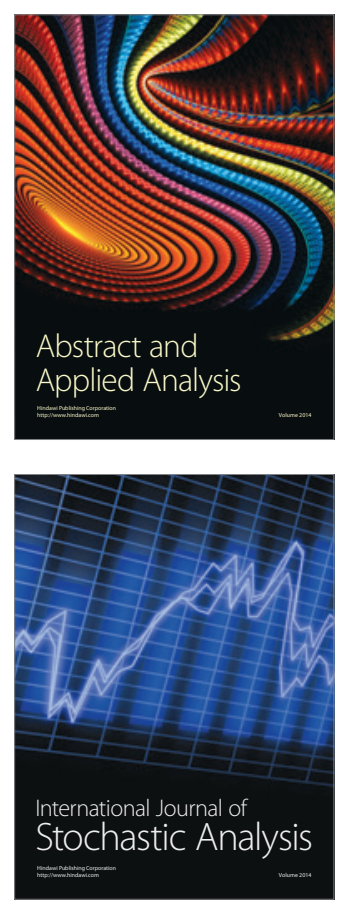

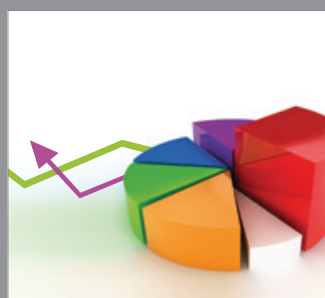

ournal of

Probability and Statistics

Promensencen
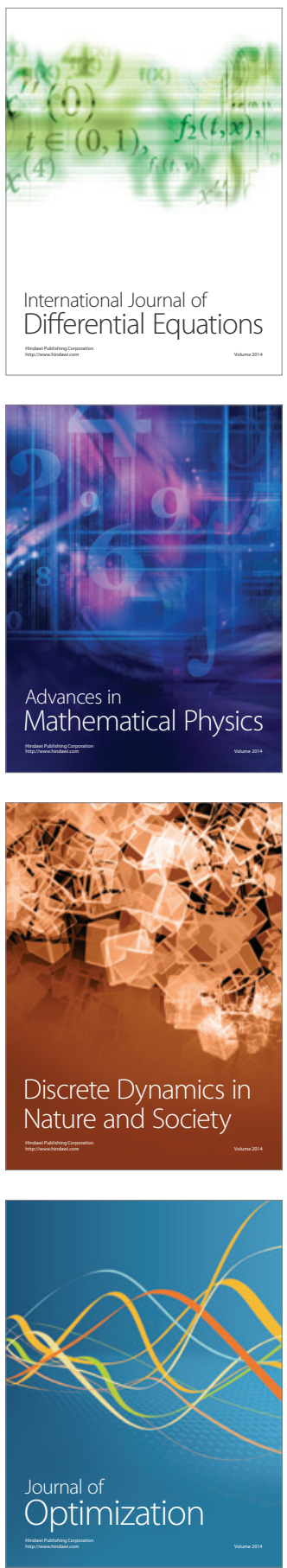